\title{
DESIGNING AN IOT BASED EMERGING MECHANISM GENERATING ELECTRIC ENERGY THROUGH SPEED BREAKER
}

\author{
Badri Narayan Mohapatra ${ }^{1 \otimes}$, Rahul Bhite $^{2}$, Abhishek N. Mehendal $^{3}$ \\ $1 \square$ Pune University, Department of Instrumentation and Control, Kenney Road, Near R.T.O., Pune, India \\ https://orcid.org/0000-0003-1906-9932, email: badri1.mohapatra@gmail.com \\ ${ }^{2}$ Final year students of AISSMSIOIT Instrumentation and Control Department, Pune University, India. \\ ${ }^{3}$ Final year students of AISSMSIOIT Instrumentation and Control Department, Pune University, India.
}

Submitted: 2018-09-24 / Accepted: 2018-12-20 / Published: 2018-12-30

\begin{abstract}
The economy of any country depends on its ability to conserve and regenerate energy. Therefore, it is a key element for the development of any country. Every second its supply is rapidly becoming exhausted in this fast and busy moving world. The continuous and dynamic rise in the world's population has a great impact on energy crisis. Due to this, an optimal method of utilising energy needs to be developed. For instance, ecofriendly solutions for vehicles. An effective generation of power can be obtained with three steps, one as linear motion to rotary and again rotary motion to produce electricity. Owing to this concept, energy can be preserved, and its implementation is essential for current situation considering a high rate of world's population.
\end{abstract}

KEYWORDS: Energy, power production, prototype model, IOT based information

\section{Introduction}

Due to population growth and surge in industrial activities the demand of electric power is increasing rapidly. Energy is an important requirement to all the sectors, so there is huge scarcity of electricity. As there is a shortage of non-renewable resources, such as petroleum, coal etc., energy may be recovered by appropriate utilisation of vehicles' mechanism i.e. speed breaker. This is an excellent solution for recovery of energy in forms of light.

The objective of this study is to generate electricity by speed breaker and provide clear information through IOT cloud system administrators for fast information. Prototype model must be developed for appropriate solutions to get clear information.

The paper is organised as follows. Section 2 illustrates the background of models used in this research and related literature. Section 3 describes the proposed research method in relation to lower utilisation of non-renewable resource and energy saving with speed breaker mechanism. Section 3 includes the way of implementation of the method as an expert mechanism. Prototypes based on real time IOT applications were given in this implementation. Section 4 describes the power calculation. Finally, the work is concluded in Section 5.

\section{Literature Review}

The three key elements of this research are electric energy generation, ESP 8266 microcontroller, to understand the algorithm, and prototype model-based mechanism. There are different power-hump mechanisms for generation of electric energy, categorised by semiconductor 
and mechanical technology, which are presented in figure 1. Speed breaker converts kinetic energy (KE) to electricity from moving vehicles so that renewable energy can be saved [1]. This is a varying recent concept for energy power generation [2]. Effective way to produce energy by replacing traditional speed breakers mechanism [8]. Rack and Pinion Mechanism for generation of energy by one form of energy to other form [3] and [5]. Speed breaker have great impact on power generation [4] and [6].

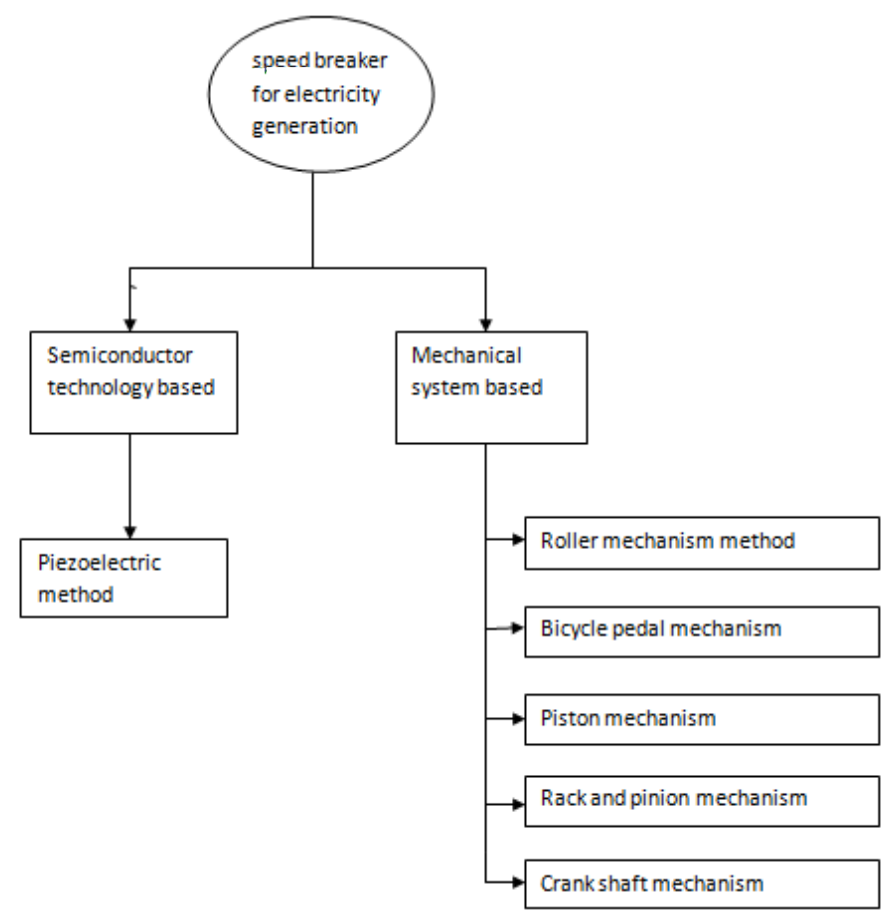

Fig. 1 Power-hump mechanism

\section{Proposed Method}

It is necessary that the arrangement should be an optimum process on the principle of kinetic energy to electricity conversion. Utilisation of mechanical and electrical technologies replaced the traditional speed breaker. Here both hardware and software are implemented to get an exact information through IOT (Internet of Things) ESP 8266 module.

\subsection{Hardware design}

The basic block diagram for the proposed mechanism is shown in figure 2. The hardware prototype model consists of a slab i.e. wood plates shown in figure 3 . When pressed down by the vehicle or by any pressure, translation motion is produced. The crank is attached to a system which contains gearbox, flywheel and generator as shown in side view figure 4. For the storing purpose, a battery is attached to an alternator. Inverter is place with the battery and a load bank is also attached. The ramp system mechanism is not like usual speed breaker, it is not harmful for vehicles. It does not only generate free energy, but the energy that has been generated is environment friendly with almost no pollution. Overall, the energy ramp system consists of two parts, hardware and software model. The both parts are shown in figure 5 . 


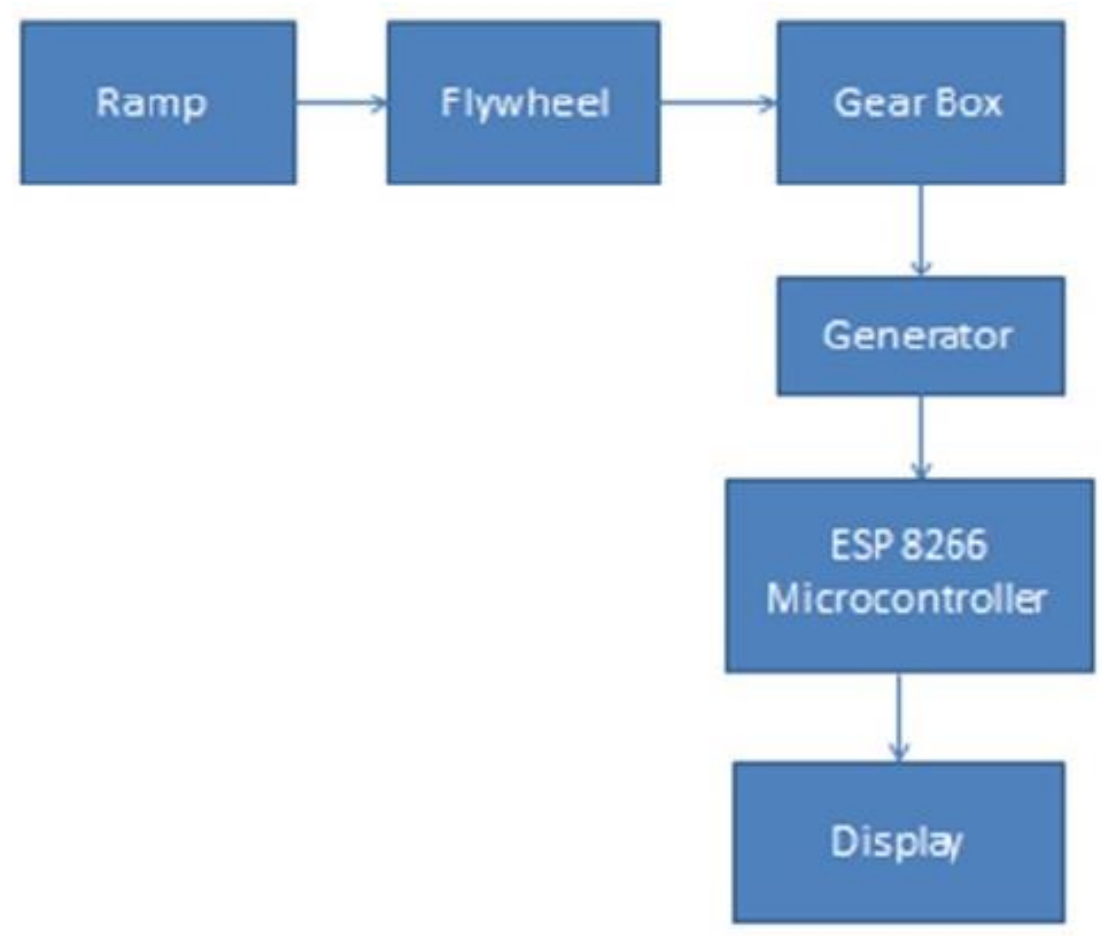

Fig. 2 Basic block diagram of energy generation

\subsubsection{Software Implementation}

Today Internet is changing the whole human life. Every manual calculation system is getting replaced by automatic emerging IOT technology. Everything can be controlled and monitored by using IOT anywhere in the world [7]. Impact on the scope of IoT utilisation for enhanced street light for smart application like energy monitoring [9]. The Internet of Things (IOT) introduced to a major smart city for automatic control in a smart way [10].

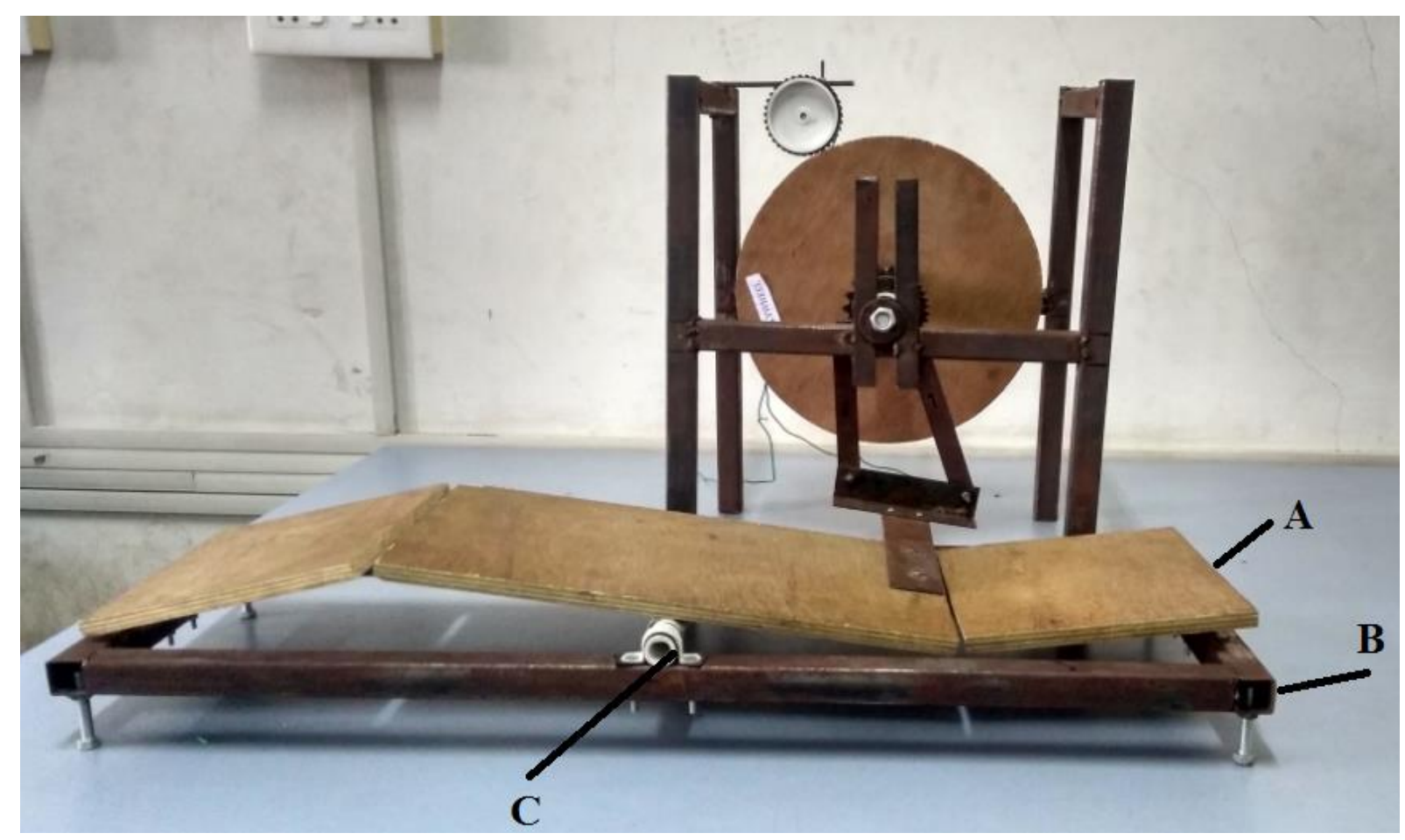

Fig. 3 Front view of the prototype model A as flat wood plate B as flat iron C as PVC pipe 


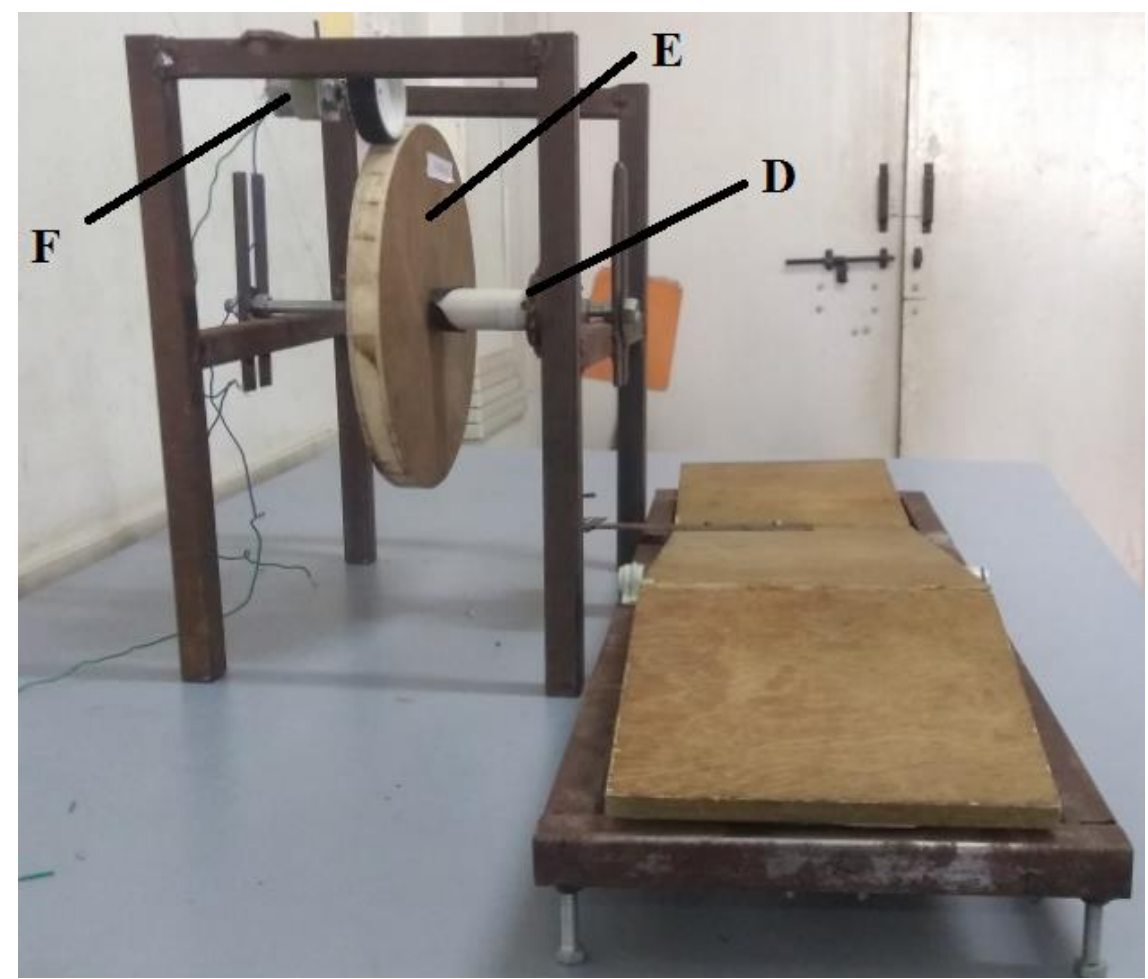

Fig. 4 Cross sectional view of the prototype where D - spur Gear, E - fly wheel, F - gear wheel motor

\subsubsection{IOT Module}

ESP 8266 is a low-cost Wi-Fi module [12] used to connect to the Internet, and it is linked to the website through which one can operate easily [11]. ESP8266 Wi-Fi module is portable, low-cost and very easy to handle [13]. Table 1 shows an idea of the ESP8266 [15]. In a mobile, this Wi-Fi device with programmed connection will give suitable information result depending upon the force applied to the wood plate as a road device. The complete program is shown in figure 6. IOT-based information can be found and analysed accordingly for any application related to electricity.

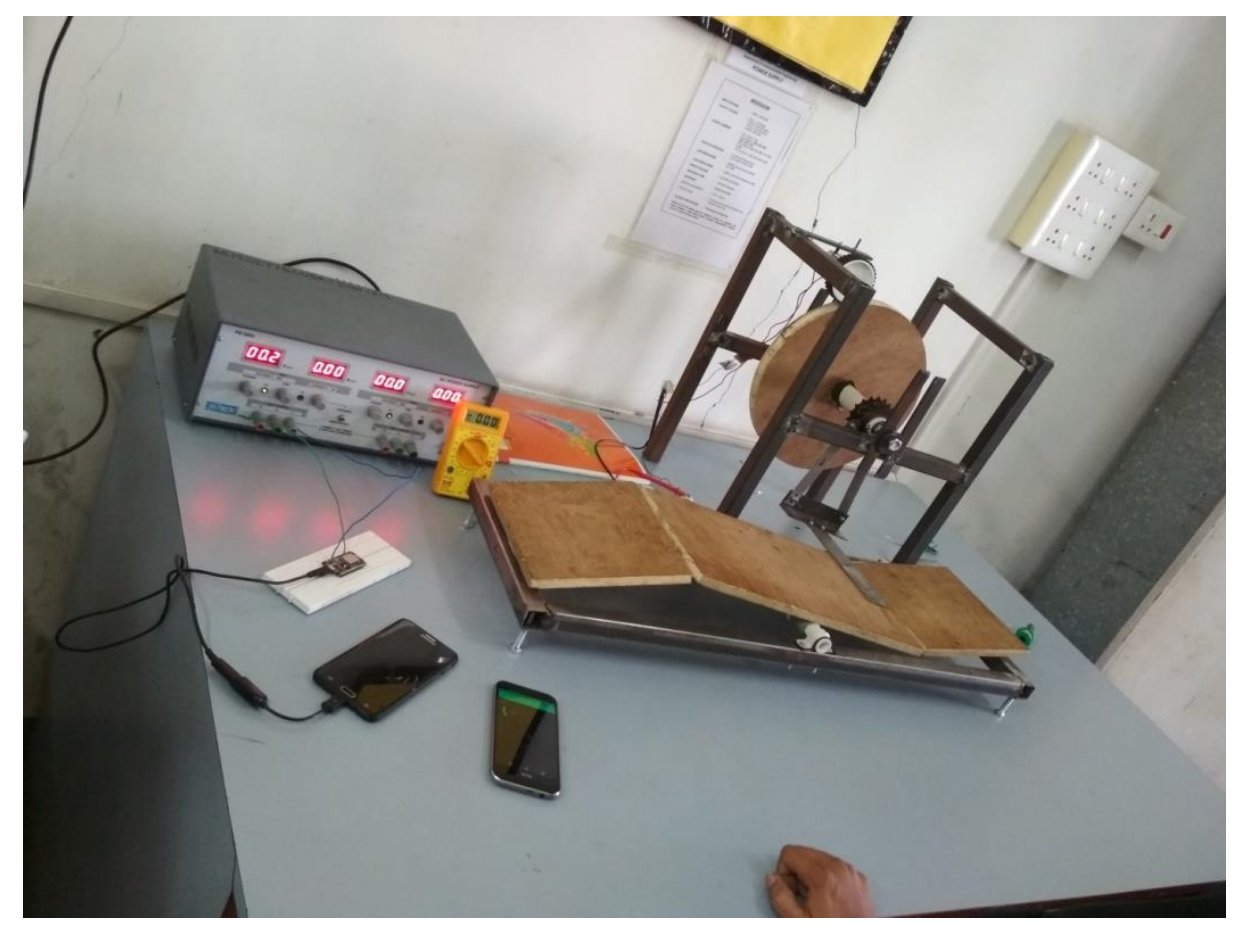

Fig. 5 IOT based Measurement 


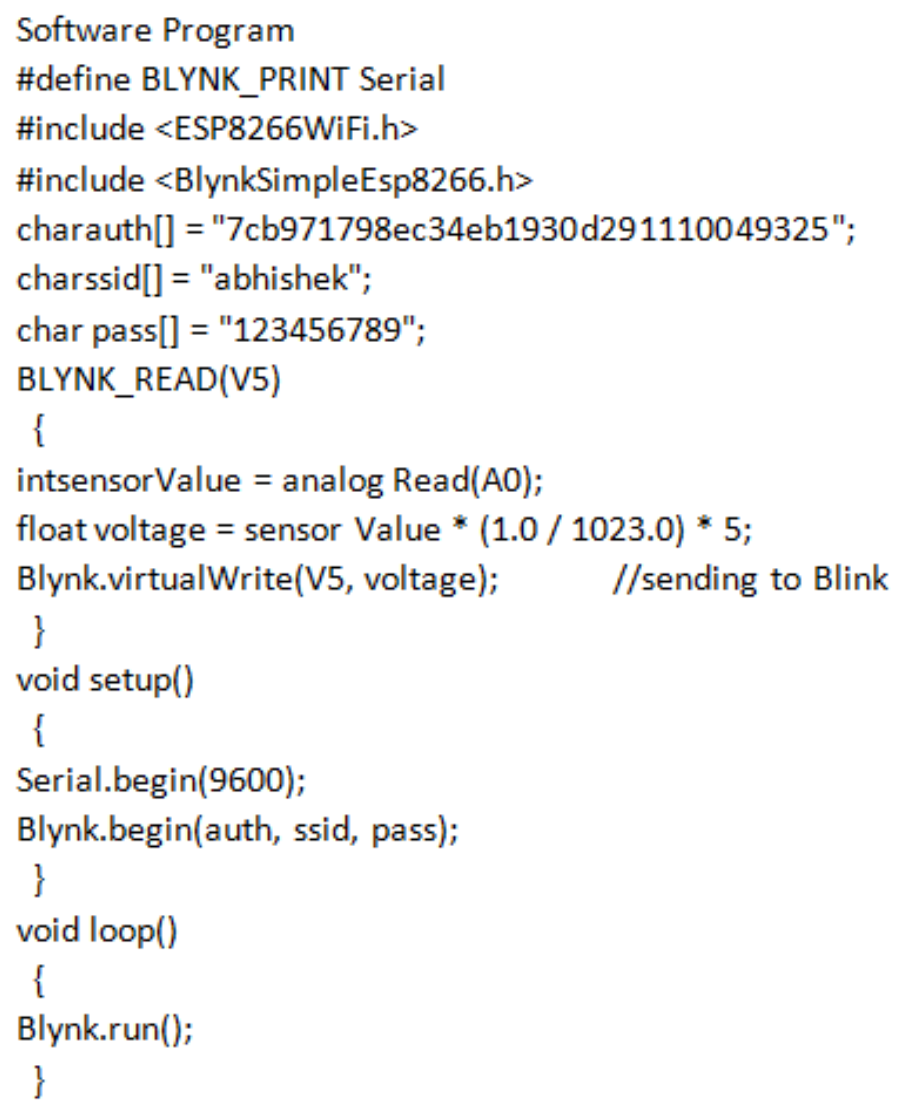

Fig. 6 Implemented program

Table 1. Information on lot Module

\begin{tabular}{|l|c|}
\hline \multicolumn{1}{|c|}{ Word } & Mass [kg] \\
\hline Type & Microcontroller/Wi-Fi (ESP 8266) \\
\hline Time line & present from 2014 \\
\hline Cost & 180 to 1100 Indian rupee \\
\hline Hardware & very low complexity \\
\hline Power & $0.00026 \mathrm{w}-0.56 \mathrm{w}$ \\
\hline Software & very low complexity \\
\hline Size & very small \\
\hline
\end{tabular}

4. Power Calculation

As work done can be calculated [14]

$W=F \times S$.

where $W$ is work, $F$-- force and $S$-- distance, and force is nothing the weight of the body or vehicle can be calculated

$l=m \times g$

Where $l$ represents load or weight of the vehicle, $m$ is the mass of the body and $g$ represents gravitational acceleration. 
If a force provided by hand is $2 \mathrm{~kg}$ then weight will be 19.6 and distance travel by the vehicle or body $15 \mathrm{~cm}$ then output power can be calculated as work done per sec.

$$
W=l \times d
$$

Where $W$ represents work, $l$ represents weight and $d$ represents displacement. So, the output power becomes $\left(19.6^{*} 0.15\right) / 60=0.049$ watt. For 60 minutes it will provide 2.49 watt. The value will be higher if more mass or weight provides force to the system. One led light only needs 6-watt power for consumption.

\section{Conclusions}

Non-conventional way of energy generation can satisfy the requirements of applications, such as suppling power to cameras and lighten city streets. Easy installation and very reliable system with promising sign for its performance. It is effective for power crises; the above mechanism can contribute to the development of the country by enriching utilisation in a useful and proficient manner. It is high time to think of energy generation from an unconventional energy sources and this energy can be stored or used as back up for other.

\section{References}

[1] Emovon, I. A. Model for determining appropriate speed breaker mechanism for power generation." J. Appl. Sci. Process Eng Vol.5, PP.256-265,2018.

[2] Olugboji, O. A., et al. "Modelling and design of an auto street light generation speed breaker mechanism." American journal of mechanical engineering Vol.3, No.3, pp.84-92,2015.

[3] Kolhe, Kiran, and Amar Pandhare "Electric Power Generation System from Speed Breaker by using Rack and Pinion Mechanism." International Journal of Current Engineering and Technology Vol7, No.3, pp.1151-1158, 2017.

[4] Prakash, Ch Bhanu, AV Ramana Rao, and P. Srinuvas. "Road power generation by speed breaker." International Journal of Engineering Trends and Technology (IJETT), and ISSN, pp.2231- 5381, 2014.

[5] Hossain, Md Emran, Md Rokib Hasan, Kazi Tahsan Ahmed, and Md Naoshat Munim Shawon. "Design and performance of power generation using speed breaker with the help of Rack and Pinion mechanism." In Advances in Electrical Engineering (ICAEE), 2017 4th International Conference on, pp. 7-11. IEEE, 2017.

[6] Santhosh, M. R., B. Shashi Kumar, and T. Yuvaraja. "Energy harvesting using speed breaker mechanism." Electrical, Electronics, Communication, Computer, and Optimization Techniques (ICEECCOT), 2017 International Conference on. IEEE, 2017.

[7] Patil, Kavita, et al. "loT based power management and controlled socket." Electrical, Electronics, Communication, Computer, and Optimization Techniques (ICEECCOT), 2017 International Conference on. IEEE, 2017.

[8] Bhagdikar, Piyush, et al. "Generation of electricity with the use of speed breakers." International Journal of Advances in Engineering and Technology Vol7, No.2, pp- 589, 2014

[9] Minoli, Daniel, Kazem Sohraby, and Benedict Occhiogrosso. "IoT considerations, requirements, and architectures for smart buildings Energy optimization and next-generation building management systems." IEEE Internet of Things Journal Vol.4 No.1 pp. 269-283,2017.

[10] Lilis, Georgios, et al. "Towards the next generation of intelligent building: An assessment study of current automation and future loT based systems with a proposal for transitional design." Sustainable cities and society 28, pp.473-481, 2017

[11] Srivastava, Prakhar, Mohit Bajaj, and Ankur Singh Rana. "IOT based controlling of hybrid energy system using ESP8266." 2018 IEEMA Engineer Infinite Conference (eTechNxT). IEEE, 2018. 
[12] Poongothai, M., P. Muthu Subramanian, and A. Rajeswari. "Design and implementation of loT based smart laboratory." 2018 5th International Conference on Industrial Engineering and Applications (ICIEA). IEEE, 2018.

[13] Zaid, Malik Muhammad, et al. "DSP Based Energy Monitoring with Online DAQ System." Open Access International Journal of Science and Engineering 2.5 x: pp.9-16, 2018.

[14] Majumdar, Sagar, et al. "Optimizing the Available Technology: Tunnel Safety and Energy Conservation System." Intelligent Communication, Control and Devices. Springer, Singapore, pp. 1361-1368, 2018.

[15] Jaffe, Samuel R. "Design of Inexpensive and Easy To Use DIY Internet of Things Platform." (2016). 